\title{
Team-Pitch-Quiz Learning Engages Students and Builds Understanding
}

\author{
Lars Oddsson ( $\mathrm{U}$ of MN \& RxFunction Inc.)
}

\author{
KEYWORDS: Health Care \& Biotech, \\ Entrepreneurship, Innovation, Teaching Methods.
}

Many of us remember that one infamous professor back in college whose boring lectures -- even on subjects that should have been interesting -- put everyone to sleep. The traditional old-fashioned lecture format simply made it mind-numbing, especially at the hands of a dull professor who assumed that if something was said, it was learned, or that the student brain is "empty" and simply talking to it will fill it up. Is there a better way maybe?

The following short article shares an alternative. It will explore the following questions: How can we as educators teach complex topics effectively? How can we make the learning process interesting and engaging for students? How can we take advantage of the various experiences, backgrounds and degrees of knowledge and expertise students bring to class? How can we challenge each individual student in a relevant manner to enhance learning? Whether the professor is teaching entrepreneurship or another topic, these challenges must be met.

In the past I have used active team-based learning models to teach anatomy and physiology. Our program is called "Team-Pitch-Quiz-Learning, or TPQL for short. The TPQL learning concept can work for other subjects and programs, too. It's a simple and engaging way to help students learn complex topics. Note that is not a literature review: team-based learning concepts have been used for decades and are described in detail elsewhere; (e.g. Collaborative Learning (Prince 2004), Problem-Based Learning (Neville 2009), and TeamBased Innovation (Nilsson et al. 2010).

\section{MS in Medical Device Innovation Program}

I teach in the Master of Science in Medical Device Innovation Program at the Technological Leadership Institute, University of Minnesota. In this 14-month program, which began in 2014, students learn from experts in the field of medical devices and gain knowledge that can help them become successful entrepreneurs or managers of innovation. I believe this program is helping Minnesota preserve its status as a world-class medical device innovation ecosystem by educating new generations of inventors and entrepreneurs, thereby providing a platform for longterm sustained economic development.

Specifically, I am responsible for a three-credit course, "Clinical Foundations of Medical Device Innovation" (MDI 5004). Other courses currently offered during the first semester of the MDI program include:

MDI 5002 Technology Foresight and Forecasting (3 credits)

MDI 5004 Clinical Foundations of Medical Device Innovation (3 credits)

MDI 5010 Product Innovation and Development Management (3 credits)

MDI 5050 Interpersonal Effectiveness and Team Dynamics (1 credit)

A number of elective courses are offered at other colleges across the University including the College of Science \& Engineering, Carlson School of Management and the Medical School. The TLI website describes the MDI degree program in further detail at this link.

Students come to the MDI program from diverse backgrounds and with various experiences and roles, commonly with a focus towards engineering (quality, mechanical, design, biomedical), clinical, regulatory and research \& development.

The typical MDI student meets the following criteria:

- One to five years of relevant work experience 
- Undergraduate degree in science or engineering

- Cumulative undergraduate GPA of 3.0 or above

- Demonstrated leadership potential

\section{Overview of the MDI course}

An ambitious curriculum has been laid out for the MDI 5004 course. One important goal of the course related to the specific focus of this article is to:

- Understand Essential Anatomy \& Physiology of the Heart \& Cardiovascular system, Gastrointestinal system, Central/Peripheral Nervous System and the Musculoskeletal System.

To achieve this goal, we use sections of the textbook: "Essentials of Anatomy and Physiology, V.C. Scanlon and T. Sanders, 7th Edition, F.A. Davis." We dedicate four sessions (of 10-12) specifically to Anatomy and Physiology. Typically, several students in a class have some basic anatomy/physiology knowledge in their background. Some may through their work experience already have deep expertise in a specific area, although some may have none. Several of the remaining sessions engage guest lecturers who are recognized experts in their respective fields. The final session of the MDI 5004 course is dedicated to individual student project presentations on a topic of their choosing related to the subject of the course.

While some students come to this class with a solid understanding of anatomy and physiology, others know very little. This is both a challenge and an opportunity when pursuing a team-based learning model. How can you effectively teach human anatomy and physiology to some 20 graduate students with diverse backgrounds in about 20 hours over a couple of weeks? The short answer is that it's not enough time to develop proficiency. However, you can teach enough basic principles and concepts to allow medical innovators to engage and communicate with clinicians and medical technical staff. The TPQL approach described below can help.

\section{Active Team-Based Learning Concepts}

The concept of Problem-Based Learning (PBL) was first introduced in the Medical School at McMaster University in 1969 (Neville 2009). It has since been adopted in numerous medical schools and has been reported to be superior to traditional learning methods (Vernon and Blake, 1993). However, Vernon and Blake also reported that PBL was not consistently defined, suggesting "a complex mixture of general teaching philosophy, learning objectives and goals, and faculty attitudes and values." It appears faculty members at different institutions may have adopted the concept of PBL to their specific learning circumstances.

The concept of Team-Based Learning (TBL) reportedly emerged from business schools experimenting with active learning concepts (Michaelsen et al. 1982, Compton et al. 2016), partly as a reaction to the high level of resources required to run a PBL program. Systematic reviews indicate that TBL, on average, helps students learn better than traditional lecturebased teaching (Kibble et al. 2016). Interestingly, TBL appears to be most beneficial for the weaker students in the cohort (Koles et al. 2010). I am unable to confirm from my experience if "weaker" students benefit more from the TPQL program. My personal opinion is that strong and weak students may benefit differently. Strong students may learn from the team experience and improve their presentation and communication skills. However, it appears likely that students with less prior knowledge of the topic at hand would benefit the most in that area. Other varieties of Team-Based Learning, including Collaborative Learning, have been described by Prince (Prince 2004). Although the model described here is not strictly $\mathrm{PBL}$ or $\mathrm{TBL}$, it includes elements of these as well as Collaborative Learning concepts. The next section will discuss the specific outline of the anatomy/physiology sessions of the MDI 5004 course.

\section{Team-Pitch-Quiz Learning: TPQL}

The model described below and illustrated in Figure 1 may be considered a hybrid of traditional, TBL and Collaborative Learning (Prince 2004). The intent was to promote and facilitate student engagement and participation in the class, thereby allowing students with knowledge in the area to contribute during team interactions, and for students new to the subject to experience a multi-sensory repetitive exposure to the topic -- i.e. to hear, see, discuss, deliberate, visualize and speak information experienced during the session. This would also benefit students with knowledge on the topic by allowing them to contribute at their own knowledge level during the Team-Work as well as the Team-Pitch phases of the session (Figure 1). Consequently, within one session a student new to the 
topic may stand in front of the class during the TeamPitch phase and present new knowledge learned and first heard about a couple of hours ago.

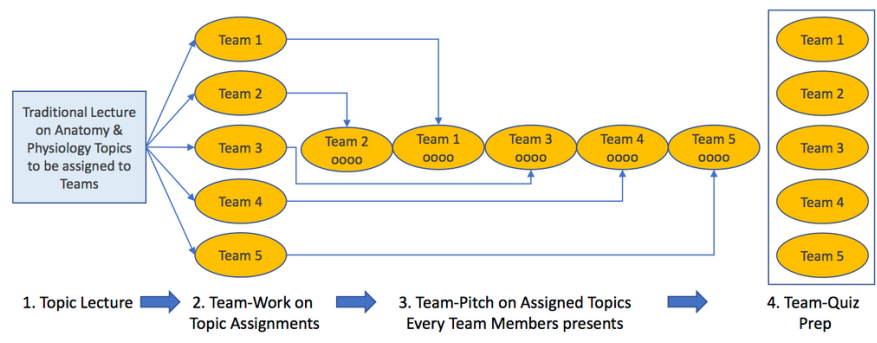

Figure 1. Overview of the Team-Pitch-Quiz Learning concept

The active Team-Pitch-Quiz Learning (TPQL) concept is illustrated in Figure 1. Students in the program are already divided into 4-5 teams according to their specific therapeutic interest, e.g. Cardiovascular, Neurological, Orthopedic, Diabetes, Cancer. Each fourhour TPQL session contains four phases. Phase 1 consists of a traditional 60- to 80-minute lecture on the specific anatomy/physiology topic at hand. The topic is known and assigned ahead of time, essentially following certain chapters of the textbook. Presumably some students prepare by reviewing the topic, although some probably come unprepared. For some students, the lecture is mostly repetition of what they already know, while for others the topic is completely new and quite challenging.

In phase two, the traditional lecture is immediately followed by the active Team-Work session where each team is assigned a certain section of the previously presented topic (Figure 1). Each team is then given the task to put together a 10- to 12-minute PowerPoint presentation on their assigned topic. This phase lasts about one hour. The team can decide to either reiterate the anatomy/physiology topic in their own words or to focus on diseases of the physiological system the team has been assigned, typically associated with their specific therapeutic interest area.

In the third Team-Pitch phase, each team stands in front of the class and presents their Team-Pitch on the assigned topic. Each member of the team presents an equal amount of time -- for example, 2-3 minutes per student. During the Team-Pitch phase, the content of the initial topic lecture is essentially repeated by the students to the students, although with a more clinical perspective. All presentations are shared with the class on Moodle for future reference.

The Team-Quiz phase is the fourth and final part of a TPQL session. This phase involves each team contributing five questions and answers related to the topic presented during the Team-Pitch to a Quiz-Pool. The five team questions for the Quiz-pool are either developed during the class session, or out of class, and should be submitted ahead of the next session.

The Quiz Pool is posted on the Moodle course site for students to access in preparation for an exam. At the end of all anatomy/physiology sessions, a selection of the Quiz-Pool questions are used for a midterm exam on the topics learned. The selection is made by the instructor and is unknown to the students. In addition, the instructor contributes about $10 \%$ of unknown questions to the exam.

\section{Some Results of the Experiences with TPQL}

- The level of knowledge that comes across in the team presentation is clearly higher than what was initially presented in the Topic Lecture, with few exceptions.

- Overall, impressive team presentations with beautiful slides, well beyond what an individual typically could accomplish in a similar setting.

- Inexperienced team members may initially appear intimidated but quickly show growing confidence at later sessions. This is typically noticed and appreciated by the whole class.

- Four members/team seems optimal for this format, three is minimal and six too many.

- Teams find very creative ways to deliver and enhance their presentations. An example: one team presenting on diseases of the skeletal system was able to call in a family member who had grown up with such a disease, thereby providing a live case study for the class. I am sure those students will never forget this "eye witness report" of the experience of living with this disease.

\section{Conclusion}

The active TPQL model briefly described here has been 
a useful teaching tool when learning basic principles and concepts of anatomy and physiology at the level required for medical innovators to engage and communicate with clinicians and medical technical staff. I think this concept could work well for other types of classes if they meet the following conditions:

- Highly motivated students who are eager to learn, have diverse backgrounds and experiences to allow all team members to contribute to the effort in a productive manner.

- Addressing a complex topic that would benefit from frequent repetition and a multi-sensory learning experience. I can see this concept working in areas of engineering, innovation and entrepreneurship, including business case discussions and business plan development.

- Beyond academia, this concept may be useful in industry when developing new long-term plans for the company.

- Encourage repetition and multi-modal sensory engagement for optimal learning -- i.e. hearing, seeing, speaking the new material etc.

- Minimal time for a class is probably about four hours. Providing for a longer period of team work as well as presentation would further enhance the benefit of the model.

\section{Acknowledgements}

I am grateful to the wonderful students of the MDI program, our future entrepreneurs, and to our friends and colleagues at the TLI, specifically Professor Dan Mooradian, Director of Graduate studies for the MDI program, and James J. Renier, Chair in Technology Management.

\section{References}

Nilsson, DAS, Hanson M, Oddsson LIE, Learning Product Design Through Globally Distributed Teams: A Way to Enhance Innovation Capabilities in Mechatronics, J. Med. Devices 4(2), 027537 (Aug 12, 2010) (1 page), doi:10.1115/1.3443765

Neville, AJ, Problem-Based Learning and Medical Education Forty Years On - A Review of Its Effects on Knowledge and Clinical Performance, Med Princ Pract 2009;18:1-9

Compton S, Kamei R, Cook S, The history and future of Team-Based Learning, Proceedings of Singapore
Healthcare 2016, Vol. 25(1) 3 -4

Kibble JD, Bellew C, Asmar A, Barkley L. Team-based learning in large enrollment classes. Adv Physiol Educ 2016, 40:435-442

Vernon DT, Blake RL, Does problem-based learning work? A meta-analysis of evaluative research. Acad Med. 1993 Jul;68(7):550-63.

Michaelsen LK, Watson WE, Cragin JP, et al. Teambased learning: A potential solution to the problems of large classes. Exchange Org Behav Teach J 1982; 7: 18-33.

Prince, M, Does Active Learning Work? A Review of the Research. Journal of Engineering Education, 2004, July, 1-10

Koles PG, Stolfi A, Borges NJ, Nelson S, Parmelee DX. The impact of team-based learning on medical students' academic performance. Acad Med 85:

Additional Search Terms: entrepreneurship courses, teaching ideas, teaching resources, classroom ideas, entrepreneurship classes, business schools, business school classes, entrepreneurship students, professors 